\title{
The Purine Salvage Pathway and the Restoration of Cerebral ATP: Implications for Brain Slice Physiology and Brain Injury
}

\author{
Bruno G. Frenguelli ${ }^{1}$ (i)
}

Received: 1 June 2017 / Revised: 14 August 2017 / Accepted: 16 August 2017 / Published online: 24 August 2017

(C) The Author(s) 2017. This article is an open access publication

\begin{abstract}
Brain slices have been the workhorse for many neuroscience labs since the pioneering work of Henry Mcllwain in the 1950s. Their utility is undisputed and their acceptance as appropriate models for the central nervous system is widespread, if not universal. However, the skeleton in the closet is that ATP levels in brain slices are lower than those found in vivo, which may have important implications for cellular physiology and plasticity. Far from this being a disadvantage, the ATP-impoverished slice can serve as a useful and experimentally-tractable surrogate for the injured brain, which experiences similar depletion of cellular ATP. We have shown that the restoration of cellular ATP in brain slices to in vivo values is possible with a simple combination of D-ribose and adenine (RibAde), two substrates for ATP synthesis. Restoration of ATP in slices to physiological levels has implications for synaptic transmission and plasticity, whilst in the injured brain in vivo RibAde shows encouraging positive results. Given that ribose, adenine, and a third compound, allopurinol, are all separately in use in man, their combined application after acute brain injury, in accelerating ATP synthesis and increasing the reservoir of the neuroprotective metabolite, adenosine, may help reduce the morbidity associated with stroke and traumatic brain injury.
\end{abstract}

Keywords ATP - Adenosine $\cdot$ Stroke $\cdot$ TBI $\cdot$ Purines . Traumatic brain injury

Bruno G. Frenguelli

b.g.frenguelli@warwick.ac.uk

1 School of Life Science, University of Warwick, Coventry CV4 7AL, UK

\section{Introduction}

\section{Brain Slices: We Have a Problem}

In the 1950s Henry McIlwain popularised the use of surgically isolated brain slices as a means to study in vitro the biochemical and electrical activity of the mammalian brain [1]. Whilst this was, and remains, an extremely valuable model system, it was clear to McIlwain that the brain slice was biochemically very different from the intact brain [2-7]. This appreciation had come from extensive studies in his own lab, but also from others, that had shown very rapid post mortem changes in the brains of animals, not least of which in ATP and phosphocreatine, which, by donating a phosphate to ADP, delays the loss of ATP (Fig. 1) [8, 9]. This rapidity of decline of ATP and phosphocreatine was understood at the time to reflect the high metabolic rate of the brain [2]. We now know that the majority of cerebral metabolism is directed primarily towards supporting synaptic transmission [10], and which explains the ATP-sparing influence of suppressing neuronal activity with anaesthesia during cerebral ischemia [11].

Whilst phosphocreatine levels could be returned close to values reported in vivo by inclusion of creatine in the incubation medium [4], and which provided reassurance as to the biochemical viability of brain slices and the general validity of the slice approach, restoring ATP levels provided to be more of a challenge. This challenge has persisted, not helped by the steep oxygen gradients found in brain slices [12-14] that may exacerbate the initial insult, hamper metabolic restitution, and indeed confound experimental observations [15, 16]. Thus, for the most part, ATP in brain slices remains at approximately $50 \%$ of the levels found in vivo. This has led to the uncharitable description of brain slices as "half dead", but there is some (metabolic) truth in Konstantin 


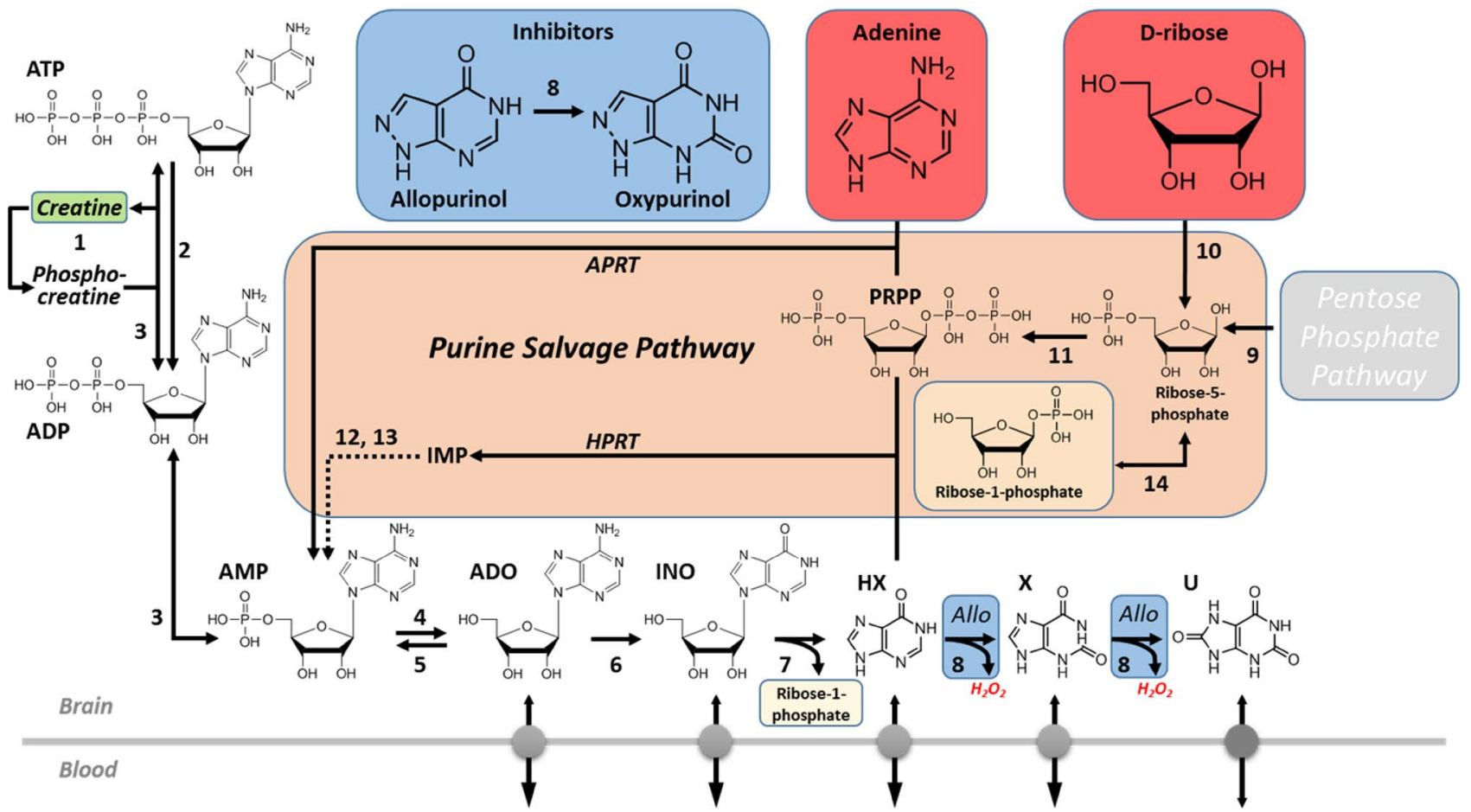

Fig. 1 Adenine nucleotide metabolism and synthesis via the purine salvage pathway. ATP breakdown results in the production of adenosine (ADO) and other metabolites that can be lost from the brain via equilibrative nucleoside transporters (light grey spheres) into the blood. The purine salvage pathway restores adenine nucleotide levels via HPRT (hypoxanthine to IMP) and APRT (adenine to AMP). These reactions require PRPP, a product of the pentose phosphate pathway from which ribose-5-phosphate emerges. Ribose-5-phosphate can be formed directly from D-ribose by ribokinase (10), or via isomerisation of inosine (INO)-derived ribose-1-phosphate (14), thereby increasing PRPP levels. Adenine and D-ribose feed into the salvage pathway and increase tissue ATP levels via adenylate kinasemediated phosphorylation of AMP and thence to ATP (3). AMP can also be formed from adenosine via adenosine kinase (5). Allopurinol (Allo), following its conversion to oxypurinol (8), prevents the break- down of hypoxanthine (HX) to xanthine (X), and from xanthine to uric acid (U). Uric acid has its own bidirectional transporter (dark grey sphere). Creatine can buffer the decline in ATP levels via creatine kinase-catalysed substrate-level phosphorylation of ADP (1). 1 creatine kinase; 2 ATPases; 3 adenylate kinases; 4 5'nucleotidase; 5 adenosine kinase; 6 adenosine deaminase; 7 purine nucleoside phosphorylase; 8 xanthine oxidase; 9 ribulose 5-phosphate isomerase; 10 ribokinase; 11 phosphoribosylpyrophosphate synthetase; 12 adenylosuccinate synthetase; 13 adenylosuccinate lyase; 14 phosphopentomutase; APRT adenine phosphoribosyltransferase; HPRT hypoxanthine-guanine phosphoribosyltransferase; PRPP phosphoribosyl pyrophosphate. Adenine/D-ribose (red), creatine (green) and allopurinol (blue) are colour-coded as they appear in subsequent figures. (Color figure online)

has signalling properties in its own right through at least seven ionotropic $\left(\mathrm{P} 2 \mathrm{X}_{1-7}\right)$ and eight $\mathrm{G}$ protein-coupled receptors (GPCRs; P2 $\mathrm{Y}_{1,2,4,6,11,12,13,14}$ ), and indirectly through its metabolism to ADP ( $\mathrm{P}_{2} \mathrm{Y}_{1,12,13}$ agonist) and adenosine, which has pronounced actions on the CNS through its four GPCRs $\left(A_{1}, A_{2 A}, A_{2 B}, A_{3}\right)$ [20]. Moreover, the ratio of ATP:AMP critically regulates the activity of AMP-activated protein kinase (AMPK), an enzyme that is known to regulate a number of ion channels and which is increasingly being implicated in a host of CNS functions $[21,22]$. Importantly for slice physiologists, the activity of AMPK is greater in slices incubated at room temperature $\left(22{ }^{\circ} \mathrm{C}\right)$ compared to $\sim 34{ }^{\circ} \mathrm{C}$ [23]. This increased activity was associated with a lower ATP:AMP ratio at room temperature, likely due to the temperature-dependence of adenylate kinase, which interconverts ATP, ADP and 
AMP (Fig. 1), and which, like many enzymes, operates optimally at physiological temperatures.

\section{Basis for ATP Depletion}

Early attempts to restore ATP levels in brain slices were made by a colleague of McIlwain's; brain slices (guinea pig cerebral cortex) fixed immediately upon preparation had adenine nucleotides at $\sim 55 \%$ of the value of brain tissue frozen in situ; slices incubated in saline fared worse, with adenine nucleotides at $\sim 30 \%$ of the in vivo value [24]. This value could be improved with the provision of adenine, inosine and, better still, adenosine in the incubation saline, but still only to $\sim 34-40 \%$ of the in situ value, with additional gains $(10 \%)$ if a cocktail of adenosine, guanine and creatine were included. A similar approach some 40 years later using adenine and adenosine yielded comparable observations, but with some neuroprotection after oxygen/glucose deprivation (OGD) afforded by adenosine [25].

Adenosine, however, is not a practical adjunct to brain slice incubation solutions given its profound actions on the CNS through its four receptors, some of which provided the neuroprotection described above [26, 27]. In the context of brain slice electrophysiology these actions include: adenosine-mediated internalisation of the inhibitory adenosine $A_{1}$ and $A_{3}$ receptors, but not the excitatory $A_{2 A}$ receptor, inhibition of neurotransmitter release, in particular of glutamate, and endocytosis of glutamate AMPA receptors [28-32]. These effects would dramatically shift the balance of excitation and inhibition in the slice preparation and be far removed from the in vivo situation where extracellular levels of adenosine are kept at a very low levels (typically submicromolar [33]). This low basal tone of adenosine occurs primarily via the actions of adenosine kinase, which maintains an inward gradient for adenosine through its conversion to AMP (Fig. 1); pharmacological or genetic manipulations of adenosine kinase have pronounced effects on extracellular adenosine and synaptic transmission [34, 35], and its upregulation in the gliosis associated with brain injury contributes to seizure activity and post-traumatic epileptogenesis [36].

Adenine, however, does have potential as an adjunct to slice incubation solutions, but not on its own. This appreciation originally stemmed from observations in the heart in which periods of anoxia or ischemia were accompanied by decreases in myocardial ATP which failed to recover upon reperfusion [37]. Various explanations were proposed, including dysfunction of mitochondria, and lactic acid and $\mathrm{pH}$ changes influencing ATP synthesising enzyme kinetics. However, one observation suggested that the basis of this prolonged post anoxic/ischemic ATP depletion was via the loss of ATP precursors from the heart and into the perfusate or blood stream [38] (similar observations were being made by Robert Berne around the same time [39]). The importance of this loss of precursors, which also occurs in man [40], stems from the fact that the heart predominately utilises the purine salvage pathway (Fig. 1) for the resynthesis of adenine nucleotides [39]. Thus, the loss of these precursors is a plausible explanation for the protracted depletion of cardiac ATP after an ischemic episode.

\section{Myocardium as a Model for ATP Replenishment}

Attempts to exploit the purine salvage pathway to restore cardiac adenine nucleotides avoided adenosine, since its profound actions on the cardiovascular system had been known since the 1920s [41], and inosine, since it too was found to exert a direct influence on the heart [42]. Instead, these repletion studies, mainly led by the labs of John Foker and Heinz-Gerd Zimmer, utilised ribose and adenine infusions in various in vitro and in vivo cardiac preparations. These studies were successful in restoring both cardiac ATP levels and cardiac function after damage caused by ischemia or adrenoceptor activation [42-46]. Indeed, such was the interest in this approach that a number of patents were filed in the 1980s [47]. However, the influence of high doses $(50 \mathrm{mg} / \mathrm{kg})$ of adenine on the cardiovascular system, its nephrotoxicity when converted to the insoluble 2,8-dihydroxyadenine, and the prolonged (24-48 h) intra-cardiac route of infusion in some studies has not seen a pursuit of this combined approach in humans. Nonetheless, ribose per se is still being considered as an adjunct to cardiac rehabilitation [48, 49], whilst for adenine, early reports of cardiac benefits of an adenine-containing mixture ("Purinor"; [50]) may have led to the continued use of Purinor in some countries.

\section{ATP Loss and Replenishment in Brain Tissue: Lessons From the Heart}

We were initially drawn to the issue of ATP levels in brain slices through observations that the release of adenosine provoked by hypoxia or OGD, which is largely responsible for the inhibition of excitatory synaptic transmission during and after metabolic stress in vitro [51-55] and in vivo [56-58], was reduced the second time the insult was delivered (Fig. 2). This manifested as a delay in the depression and acceleration in the recovery of excitatory synaptic transmission [59]. Whilst this could reflect an artefact of the slice preparation, similar observations of reduced adenosine release were being made around that time in in vivo preparations [60-62]. Furthermore, it was known that such repetitive insults to the brain could provoke greater brain damage [63], a fact that is of great current concern in the context of sport-related concussions [64]. Thus, these observations of ATP and adenosine depletion had potential clinical importance [65]. 


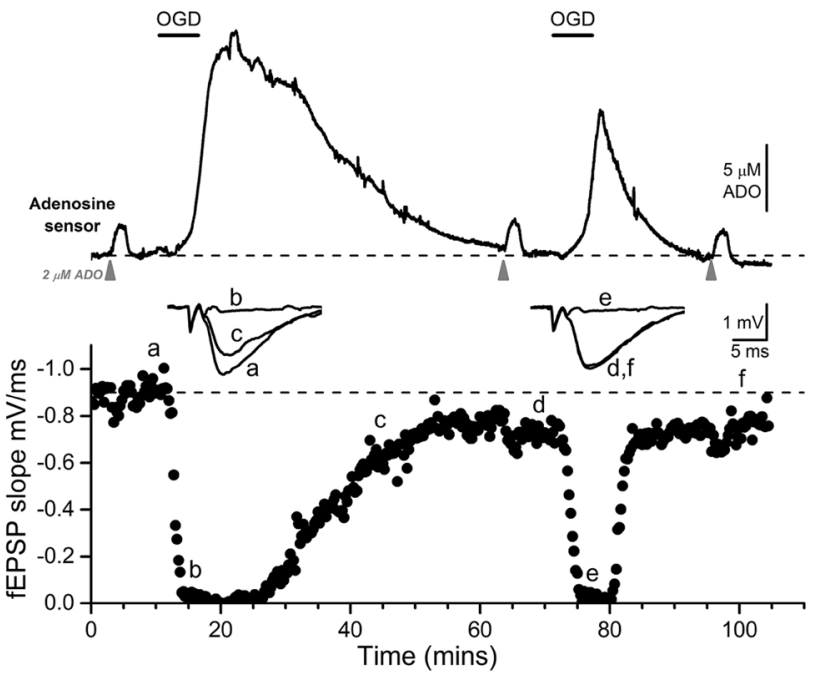

Fig. 2 Evidence for adenosine depletion in area CA1 of hippocampal slices. Top panel shows adenosine sensor measurements of adenosine (ADO) release in response to two identical periods of oxygen/ glucose deprivation (OGD, 6 min, black bar). Lower panel shows the depression and recovery of the simultaneously recorded fEPSP. Inset are fEPSPs taken at the times indicated. Note the reduced release of adenosine and reduced effects on the fEPSP during the second period (compare fEPSPs $c$ and $f$ taken at comparable times after OGD). Grey triangles refer to applications of exogenous adenosine $(2 \mu \mathrm{M})$ to test that the sensor has not run down over this period. In these experiments, differential measurements were made between adenosine and inosine biosensors resulting in net adenosine release being detected. Adapted from [33]

One possibility was that the reduced adenosine release reflected a depletion of the primary reservoir for adenosine, ATP. This was plausible as the brain, like the heart, relies largely upon the purine salvage pathway for the restoration of adenine nucleotides, as de novo synthesis is slow and not increased after metabolic stress [66-68]. Indeed, that the substrates of the purine salvage pathway (Fig. 1) are depleted in the ischemic brain are dramatically demonstrated by Matrix Assisted Laser Desorption/Ionization (MALDI) imaging [69] of ex vivo ischemic brain tissue. Such studies have revealed the loss of ATP, ADP, AMP, adenosine, inosine, hypoxanthine and ribose-5 phosphate in the ischemic core, but with accumulations of the non-salvageable xanthine and uric acid [70, 71].

Accordingly, the release of adenosine into the perfusate could, as in the heart, represent a loss of substrates for the purine salvage pathway. That the release of adenosine and other purines has been observed in the blood stream in humans experiencing cerebral ischemia [72] lends support to this possibility, and potentially explains the protracted recovery of cerebral bioenergetics after concussion [73]. Moreover, purines in the blood could serve as rapid diagnostics for stroke.

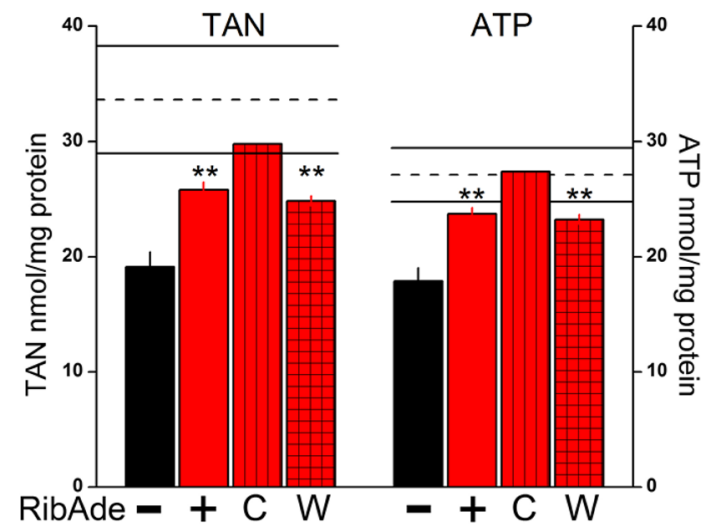

Fig. 3 Ribose and adenine (RibAde) elevate brain slice adenine nucleotides. Incubation in RibAde (+; solid red bar) increased total adenine nucleotide content (TAN; $\Sigma(\mathrm{ATP}+\mathrm{ADP}+\mathrm{AMP})$ ) and ATP levels above control levels in hippocampal slices (-; black bar). This increase persisted upon washout of RibAde from the incubation medium (W; $2 \mathrm{~h}$; checked red bar). When TAN and ATP levels were corrected for the dead edges of slices ( $\mathrm{C}$; vertical hatched red bar), slice TAN and ATP were within the range reported in vivo (mean, dashed line; solid lines $\pm 1 \mathrm{SD}$; references found in [23]). **p $<0.01$ sig diff from control slices (-). Adapted from [23]. (Color figure online)

Attempts to reverse adenosine depletion via the provision of exogenous adenosine were successful [59], suggesting that the slice had the capacity to restore its depletable pool of both adenosine and, by inference from the work of Thomas [24], ATP. Given the limitations of adenosine described above, we subsequently adopted the ribose/adenine approach pioneered in the heart.

We initially confirmed observations made on numerous occasions previously eg $[74,75]$ as to the impoverished level of ATP in hippocampal slices, even when slices are incubated in supra-physiological levels of glucose (10 mM; Fig. 2) [23]. We additionally examined the energy charge (EC) [76] of the slices, which conveys the energetic state of a cell and is given by the following equation:

$E C=\frac{[A T P]+0.5[A D P]}{[A T P]+[A D P]+[A M P]}$

such that if all the adenine nucleotides were in the form of ATP energy charge would equal 1, whilst if only AMP was found the energy charge would equal 0 . We found that, despite the attenuation in ATP levels, EC was close to values recorded in vivo (typically $\sim 0.95$ ) $[23,77]$. This suggests that a new metabolic equilibrium had been achieved amongst the remaining adenine nucleotides. This was only true, however, if care was taken to extract adenine nucleotides from neutralised fresh tissue; freeze-thawed tissue showed EC values similar to those widely reported for brain slices $(<0.9)$ [77]. 
Incubation of hippocampal slices (with overlying neocortex), from the time of cutting, in $10 \mathrm{mM}$ glucose-containing aCSF supplemented with modest concentrations of ribose $(1 \mathrm{mM})$ and adenine $(50 \mu \mathrm{M}$; "RibAde") resulted in increases in the total adenine nucleotide (TAN) and ATP content after 2-3 h (Fig. 3; [23]). Neither were effective alone, and this seemed to be the optimal concentration of both compounds since increases in either did not improve ATP levels (or the EC) any further. The increase in cellular ATP was stable in that removal of slices from RibAde-containing aCSF to control aCSF still resulted in elevated ATP after at least $2 \mathrm{~h}$. Moreover, compensating for the dead cut edges of slices (which contribute protein, but no ATP to the normalisation to protein content) resulted in estimates of tissue adenine nucleotides that were within the range reported in vivo, with estimates of ATP being within a few percent of that measured from the rapidly fixed brain (Fig. 3). This interesting result, together with the inability of higher concentrations of RibAde to enhance ATP levels further, suggests an optimal level of ATP that may be limited by feedback inhibition on ATP-synthesising enzymes [67].

\section{The Purine Salvage Pathway as the Vehicle for ATP Replenishment}

The most likely route by which this ATP is synthesised following the provision of RibAde is via the purine salvage pathway, the enzymes of which are found in brain and, importantly, are located in the cytosol $[67,78]$ and provide an energetically-efficient means to resynthesise adenine nucleotides (Fig. 1). Provision of exogenous ribose and its phosphorylation by ribokinase to ribose-5-phosphate bypasses the pentose phosphate pathway and is a more direct route by which the cellular PRPP pool can be increased. Endogenous ribose-1-phosphate derived from inosine can be converted to ribose-5-phosphate by phosphopentomutases [79] and hence PRPP (Fig. 1) and this has been described as the main route by which purines are salvaged [67]. The importance of the PRPP pool stems from the fact that it contributes the phosphoribose moiety to adenine and hypoxanthine to generate AMP and IMP via adenine phosphoribosyltransferase (APRT) and hypoxanthine-guanine phosophoribosyltransferase (HPRT), respectively. Both enzymes are expressed in neurones and astrocytes, with similar levels of APRT, but greater expression of HPRT in neurones [80]; mutations in HPRT are responsible for Lesch-Nyhan disease [81]. Two further steps convert IMP to AMP, which can then be converted to ATP via adenylate kinases [68].

Adenylate kinases are interesting enzymes in that there are nine isoforms, several of which are found in brain and localised to the cytosol [82]. Moreover, most isoforms possess both nucleoside monophosphate (eg AMP $\rightarrow$ ADP) and nucleoside diphosphate (eg ADP $\rightarrow$ ATP) kinase activity and are capable of utilising phosphate donors other than ATP. This diversity of action and promiscuity in the phosphate donor ensures that a futile cycle of robbing AT(Peter) to pay $\mathrm{AD}$ (Paul) does not ensue, but instead the net result is in the generation of cytosolic ATP. In highly polarised cells, such as neurones, having an extra-mitochondrial source of ATP, including via creatine kinase, is very valuable as mitochondria may be remote from the site of neuronal activity. Recent detailed serial electron microscopic reconstructions of the mature neocortex showed that mitochondria were located in only a small fraction of dendritic spines ( 3 out of 1425 spines) [83]. This contrasts with the situation in primary neuronal cultures where mitochondria or their protrusions may enter postsynaptic spines in an activity-dependent manner [84].

The cytosolic location of the enzymes involved in purine salvage pathway and the conversion of AMP to ATP (Fig. 1) indicates that the local synthesis/replenishment of ATP can occur at sites of high activity and independently of mitochondria, at least in the short-term, and may permit the "on-demand" nature of synaptic adenosine release which dampens presynaptic excitation [85-88]. This local, extra-mitochondrial, generation of ATP has an important additional advantage in the context of brain injury due to the mitochondrial dysfunction that can follow. Such injury-induced dysfunction of mitochondria (including that incurred after slice preparation [89]) can provoke a host of events including mitochondrial consumption of cytosolic ATP, and the liberation of reactive oxygen species and proapoptotic factors, all of which would contribute to cellular damage [90-92]. It should also be remembered that the extra-mitochondrial purine salvage pathway and adenosine kinase are the mechanisms by which the adenine nucleotide backbone is constructed in the form of AMP. Mitochondria absolutely rely upon this to import cytosolic ADP and generate ATP via oxidative phosphorylation or mitochondrial adenylate kinases. This may explain the limited success of strategies designed to promote ATP synthesis via provision of TCA precursors or intermediates such as lactate or pyruvate [93], or ketones [94] in the context of acute brain injury. These substances do not generally elevate brain slice ATP levels, [95-97], and nor indeed does creatine [98], likely because the adenine nucleotide backbone is not available.

\section{LTP in ATP-Replenished Brain Slices: Not What You'd Expect}

Having now produced slices with physiological levels of cellular ATP, an obvious question was to determine the influence that this would have on long-term potentiation (LTP). Our expectation was that creating such "healthy" slices, LTP would be enhanced or at least facilitated. In contrast, despite there being no effect on basal synaptic transmission 
A
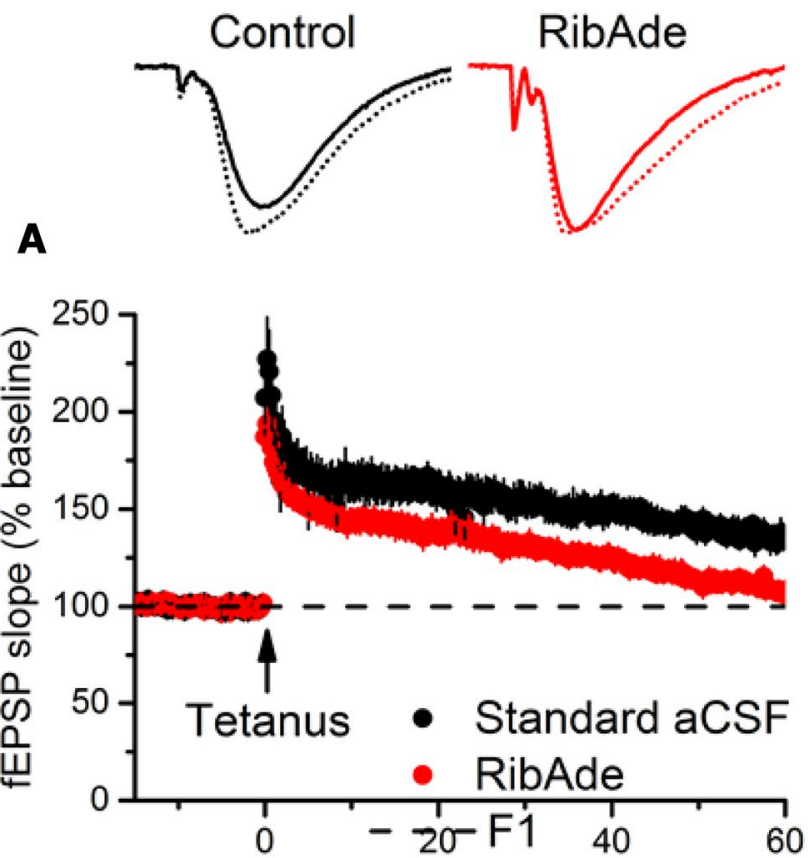

C

Time (min)

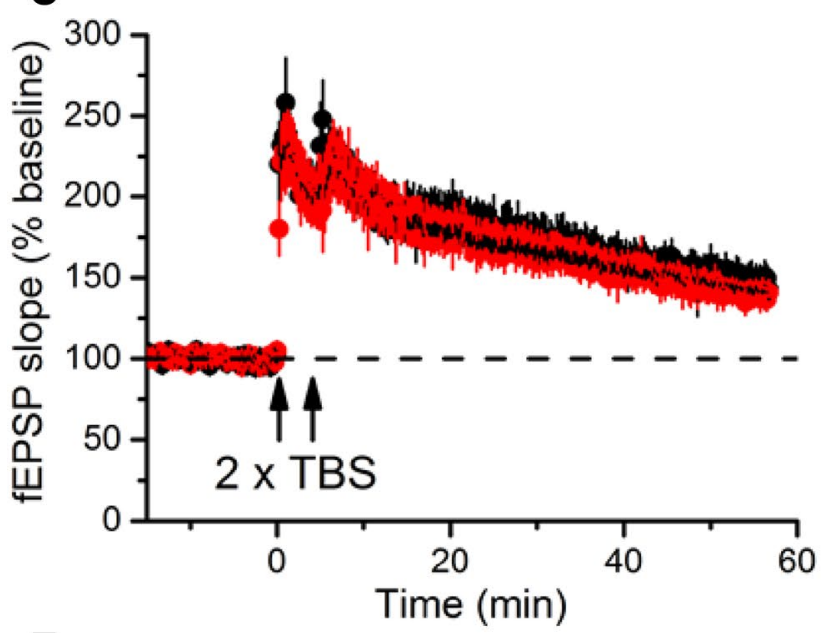

E

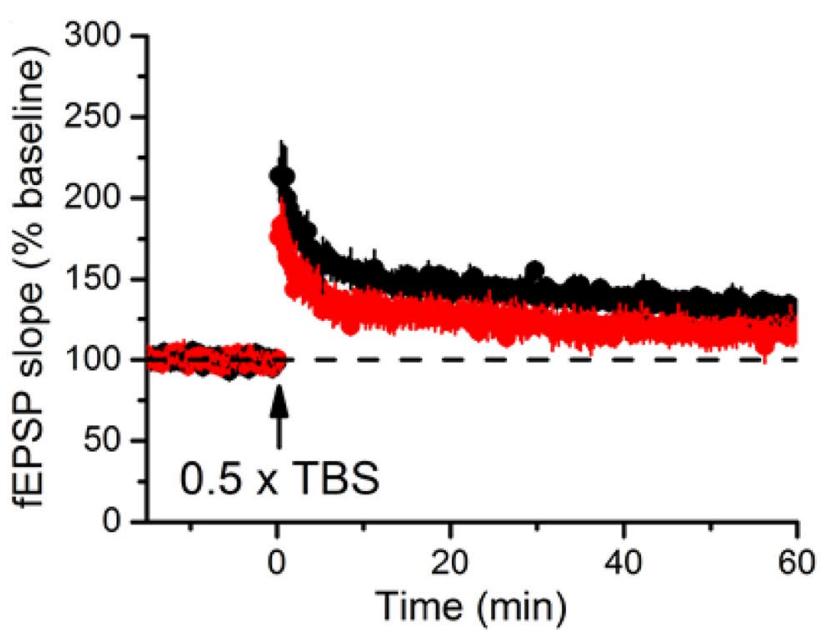

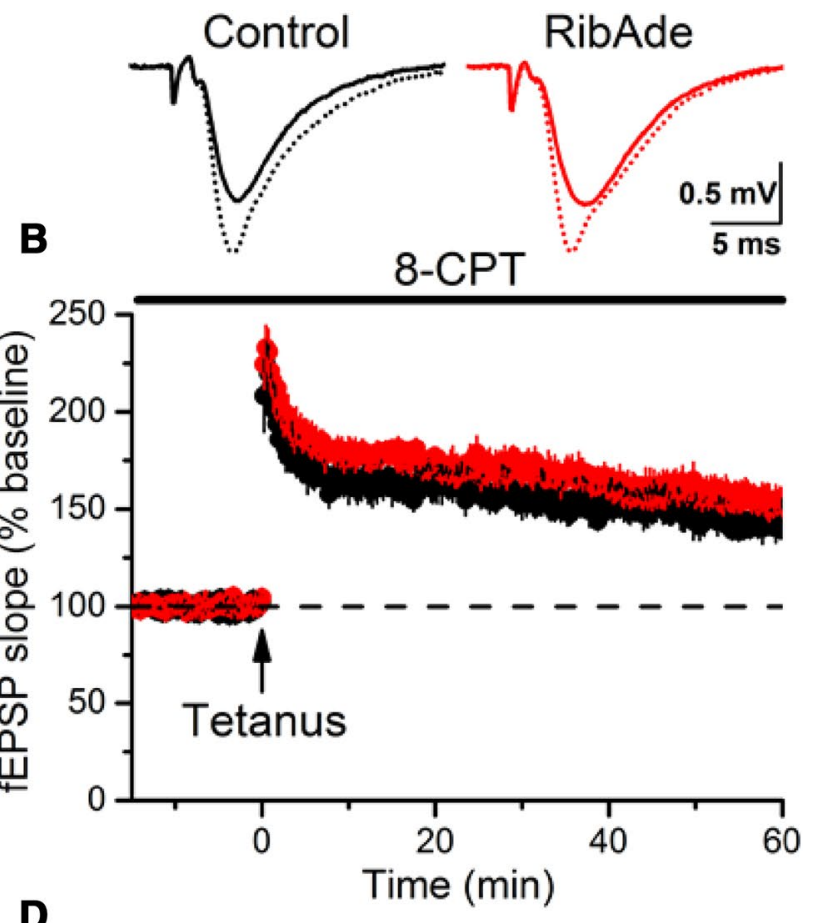

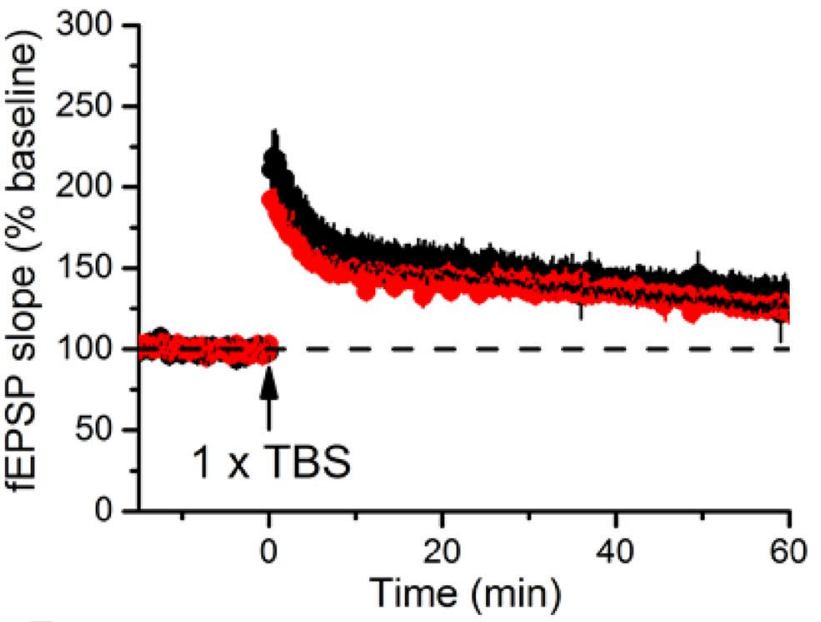

$\mathbf{F}$

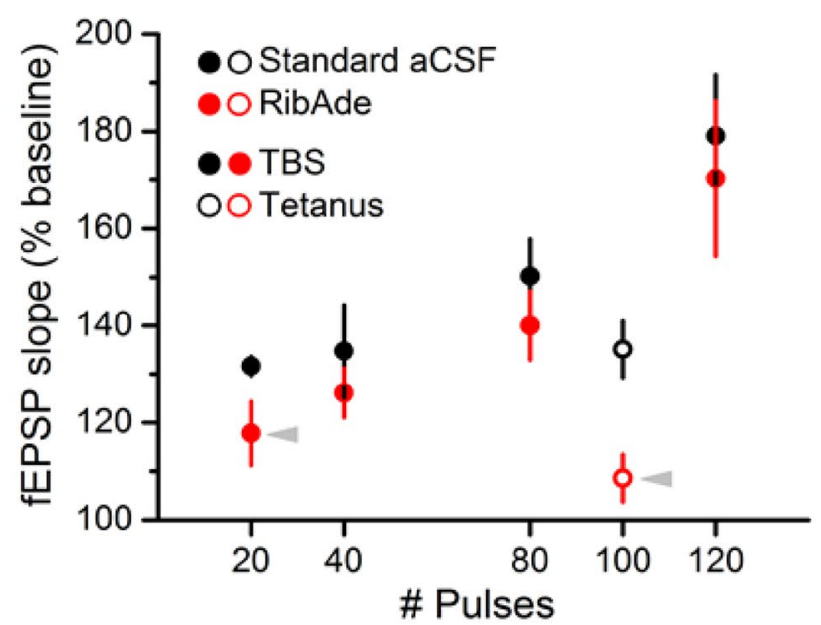


४Fig. 4 Elevating cellular ATP with RibAde inhibits LTP via adenosine $\mathrm{A}_{1}$ Rs. A LTP induced by a tetanus $(100 \mathrm{~Hz} / 1 \mathrm{~s}$; arrow $)$ resulted in robust LTP in standard aCSF, but steadily decremented to baseline in slices pre-incubated in RibAde. B This decrementing LTP was prevented by the adenosine $\mathrm{A}_{1} \mathrm{R}$ antagonist 8-CPT $(1 \mu \mathrm{M})$. Inset are fEPSPs taken before (solid lines) and at $60 \mathrm{~min}$ after the induction of LTP (dashed lines) in standard aCSF (control) and RibAdetreated slices. C-E Decreasing the number of TBS pulses (80, 40, 20, respectively) induced LTP, which is consistently lower in RibAdetreated slices. 20 TBS pulses $(0.5 \times$ TBS; E) failed to induce significant LTP above baseline. F Summary of LTP at $60 \mathrm{~min}$ induced in (A) (tetanus; open symbols), C-E Data for 120 pulses from the LTP (at $30 \mathrm{~min}$ ) induced by $3 \times$ TBS used to evoke the adenosine release in Fig. 5A. Grey arrowheads indicate where LTP was not significantly greater than baseline in RibAde-treated slices. A two-way ANOVA (standard aCSF or RibAde treatment vs number of pulses) showed a significant effect of treatment on the LTP evoked by the various stimulation protocols $\left(\mathrm{F}_{1,51}=6.47688 ; \mathrm{p}=0.014\right)$. Adapted from [23]

or paired-pulse facilitation of RibAde treatment, LTP in response to a $1 \mathrm{~s}$ tetanus was inhibited (Fig. 4A). We were able to establish, using an adenosine $A_{1}$ receptor $\left(A_{1} R\right)$ antagonist that this was due to greater activity-dependent release of adenosine and activation of inhibitory adenosine $\mathrm{A}_{1}$ receptors in RibAde-treated slices (Fig. 4B). To establish whether this inhibition of LTP was specific to tetanusinduced LTP, we performed theta-burst stimulation (TBS; Fig. 4C-E) LTP using multiples (2, 1, 0.5, respectively) of a 40 pulse TBS protocol [23]. This induced LTP that was consistently smaller in RibAde-treated slices (Fig. 4F). Indeed, LTP was not significantly induced in RibAde-treated slices given 20 pulses ( $0.5 \times$ TBS; Fig. $4 \mathrm{E})$.

We surmised that the greater cellular ATP pool had provided for a larger releasable pool of adenosine. Measurements using adenosine biosensors confirmed this supposition (Fig. 5A). That this adenosine was released as such, and not as ATP, was suggested by the lack of effect of the ectonucleotidase inhibitor POM-1 [99] on evoked adenosine release. That neuronal activity caused by electrical stimulation results in the breakdown of cellular high-energy phosphates has been known for quite some time [2], as has the fact that this then results in the release of adenosine [100].

An examination of the fEPSP depolarising envelope evoked by $100 \mathrm{~Hz}$ stimulation revealed a fatigue of the fEPSP after approximately 20 pulses, which was exaggerated in RibAde-treated slices (Fig. 5B) and which indeed was the number of pulses that failed to induce TBS LTP in RibAde-treated slices (Fig. 4E). This RibAde-induced enhancement of fatigue, as per the inhibition of tetanus-LTP (Fig. 4B), reversed upon treatment with the $\mathrm{A}_{1} \mathrm{R}$ antagonist 8-CPT (Fig. 5C). During TBS the depolarising envelope in response to 40 pulses (1 $\times$ TBS), in contrast to the situation with the tetanus, showed was no such fatigue of the fEPSP, and indeed no obvious effect of RibAde. This implies that, in addition to the two properties of TBS that makes it effective in inducing LTP, maximising both postsynaptic depolarisation (by preventing depolarisation block and transmitter depletion) and fatigue of inhibitory GABAergic transmission, we may potentially add a third-preventing the synaptic accumulation of adenosine during synaptic activity. However, since LTP was reduced by RibAde, some inhibitory action of adenosine must occur post-induction, which is reminiscent of observations made by Gary Lynch in the 1990s regarding an early phase of LTP sensitive to adenosine [101]. Direct measurements of adenosine release in response to TBS demonstrates the persistence of adenosine in the extracellular space after the induction of LTP during the early sensitive period (Fig. 5A).

\section{ATP and OGD}

Given that our interest in the fate of ATP and adenosine arose from work conducted in the context of OGD, we returned to this issue to examine the effects of metabolic stress in slices preincubated in RibAde. We predicted that the enhanced levels of ATP should result in greater adenosine-mediated inhibitory actions on excitatory synaptic transmission. As a comparator, we performed additional studies using creatine $(1 \mathrm{mM})$. By buffering the decline in cellular ATP through the creatine kinase-mediated phosphotransfer from phosphocreatine to ADP, ATP levels are preserved, and should result in a delay and reduction in the appearance of extracellular adenosine, with subsequent reduced inhibitory effects on excitatory synaptic transmission. These predictions were borne out [98] (Fig. 6) and furthermore demonstrated that previous observations [102] concerning the sparing of synaptic transmission and neuronal excitability by creatine were not entirely due to better ATP-dependent support for neurotransmitter release per se, but by reduced extracellular adenosine release. Similar observations of RibAde and creatine facilitating and reducing adenosine release during seizure activity, with inhibitory and excitatory actions on neuronal activity, respectively, have been made in an in vitro model of epileptiform activity [103]. This suggests that the seizure-induced depletion of intracellular ATP contributes to the rapid accumulation of extracellular adenosine to limit the duration, frequency and intensity of seizures [33].

\section{Therapeutic Potential of RibAde-Based Therapy}

Given the ability of RibAde to: elevate ATP levels in the injured brain (slice); increase the release of neuroprotective adenosine in response to physiological and pathological stimuli; exert an adenosine $\mathrm{A}_{1} \mathrm{R}$-dependent inhibitory influence on excitatory synaptic transmission, and indeed to protect cerebellar granule cells when administered after OGD [98], to what extent might RibAde-based therapy be of value in the injured human brain? This would depend upon two key factors, namely (1) the safety and tolerability 


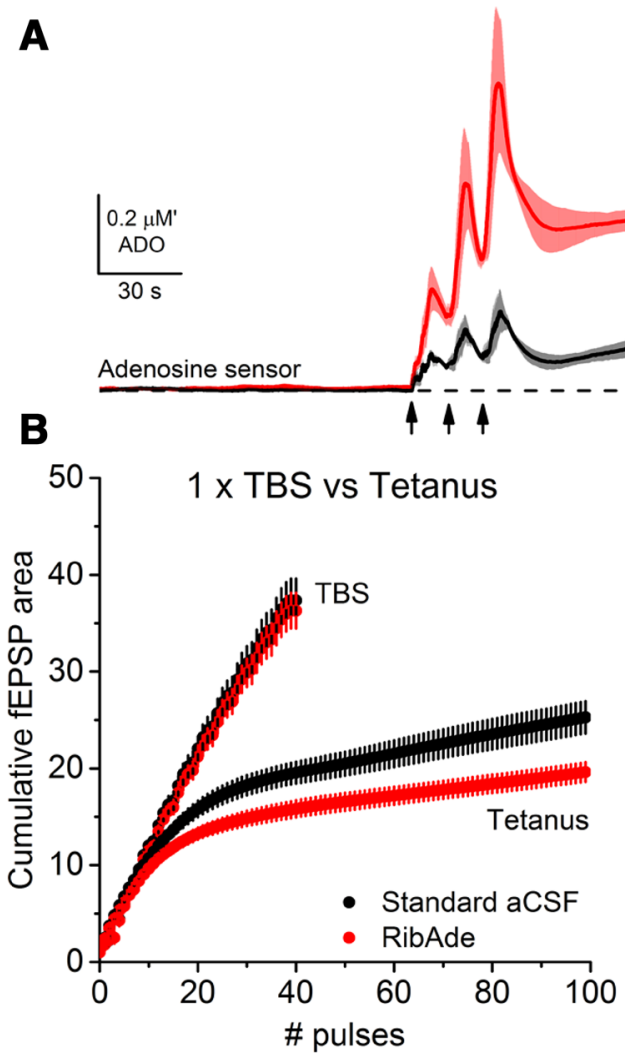

Fig. 5 Adenosine release during high-frequency stimulation. A RibAde increased adenosine release (ADO) in response to TBS (arrows). Note the release per individual theta burst (10 trains at $5 \mathrm{~Hz}$ of 4 pulses at $100 \mathrm{~Hz}$ ) and the sustained post-TBS elevation of adenosine, which may be responsible for the subsequent inhibition of LTP seen in Fig. 4A. In these experiments the biosensor measures the signal recorded from an adenosine sensor, which is sensitive to adenosine and its metabolites (inosine, hypoxanthine and xanthine). The concentration is thus given as $\mu \mathrm{M}^{\prime}$ to indicate that it is not purely

of ribose and adenine, and (2) the extent to which they can cross the blood-brain barrier from the systemic circulation.

\section{Safety and Tolerability}

On the former, ribose is widely sold as an unregulated nutritional supplement, and large quantities can be ingested orally with few side effects [104]. In terms of its intravenous delivery, escalating doses of ribose were administered intravenously for $12 \mathrm{~h}$ in humans until $220 \mathrm{mg} / \mathrm{kg}$ was administered for $4 \mathrm{~h}$ [105]; this dose is higher than that used by Zimmer in animal models $(200 \mathrm{mg} / \mathrm{kg}$ ). The study by Gross and Zöllner was designed to investigate the mild blood glucose-lowering ability of ribose (20-25\%), which has been known since the 1940 s. However, in the context of the injured brain, glucoselowering therapies may mitigate against the damage caused by injury-induced hyperglycaemia [106] and may thus be an additional benefit of ribose-based therapy.

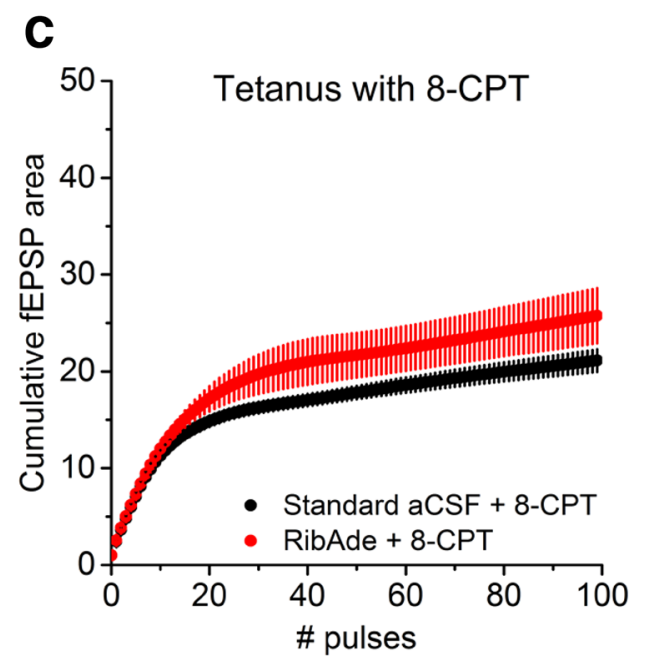

adenosine that is detected. B The envelope of depolarisation evoked by tetanic stimulation fatigues after $\sim 20$ pulses, an effect that was enhanced by RibAde. This is likely via increased adenosine release since $(\mathbf{C})$ this effect was reversed by the $A_{1} R$ antagonist 8 -CPT. In contrast, the cumulative depolarisation evoked by TBS (B) was unaffected by RibAde, suggesting that spacing between bursts (200 ms) was sufficient to allow lowering of synaptic adenosine to the point that it does not interfere with synaptic transmission, at least during the period of high-frequency stimulation. Adapted from [23]

Adenine is used to support red blood cell ATP production in blood transfusion products. Red blood cells lack both mitochondria and de novo synthesis of adenine nucleotides and thus rely on the purine salvage pathway. Inclusion of adenine in red blood cell transfusion products doubled the shelf-life of fresh blood from 3 to 6 weeks, whilst some experimental adenine-containing solutions can extend viability to 8-10 weeks [107]. High doses of adenine, however, result in toxicity and pathology associated with the xanthine oxidase-mediated conversion of adenine to the insoluble 2,8 dihydroxyadenine, which forms crystals, primarily in the kidney. This occurs in APRT deficiency, but can be managed via the use of the xanthine oxidase inhibitor, allopurinol [108]. Given this concern, the introduction of adenine as a component of blood transfusion products was delayed in some countries until extensive animal and human studies established safe limits for intravenous infusion, which are in the region of $10-15 \mathrm{mg} / \mathrm{kg}$ [109]. However, simulations of 


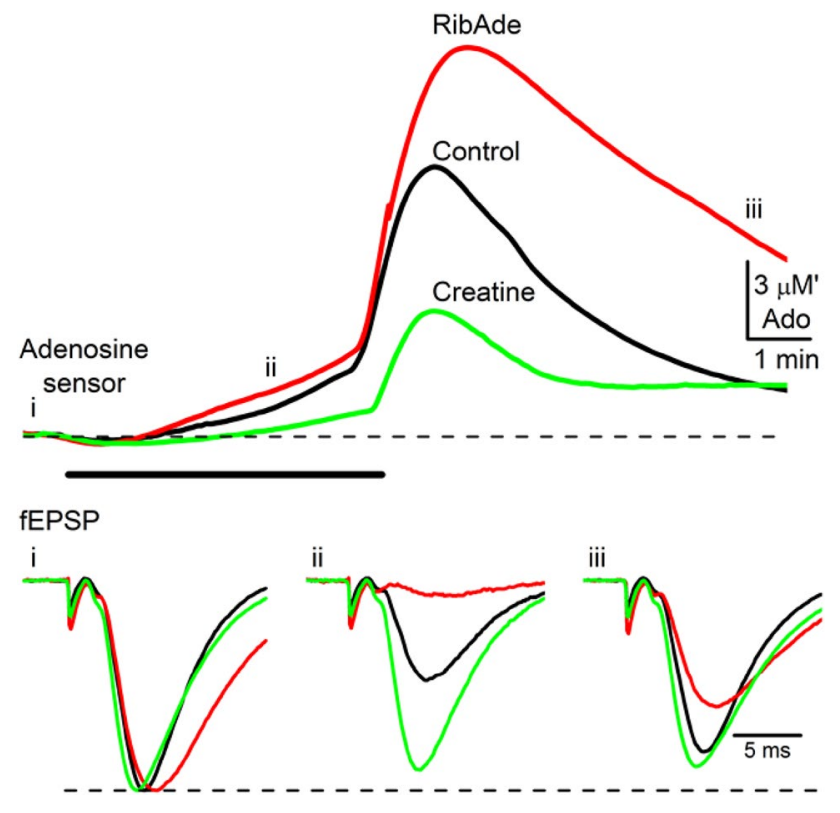

Fig. 6 Modulation of intracellular ATP influences adenosine release and synaptic transmission during metabolic stress. Upper panel shows adenosine (ADO) release in response to a $5 \mathrm{~min}$ period of oxygen/glucose deprivation (OGD, black bar) in control slices, and slices pre-incubated in RibAde and creatine. Note greater release of adenosine in RibAde-treated slices and reduced release in slices pre-incubated in creatine (mean of 4 traces for each condition shown). Lower traces show fEPSPs, taken at the times indicated and colour-coded as per adenosine release, demonstrating the (ii) accelerated depression and (iii) delayed recovery of synaptic transmission in RibAde-treated slices compared to the delayed depression and accelerated recovery in creatine-treated slices. These observations are in keeping with the enhanced adenosine release caused by RibAde, and the reduced adenosine release caused by creatine. fEPSPs have been normalised to the pre-OGD amplitude, which is indicated by the dashed line. Adapted from [98]

massive blood transfusions at that time indicated that higher doses (up to $100 \mathrm{mg} / \mathrm{kg}$ ) could be tolerated in non-human primates [110], and indeed there appears to be only one report of adenine-based kidney damage in humans having received massive blood transfusions subsequent to major trauma or obstetric haemorrhage [111]. Thus, whilst there are potential issues associated with adenine, the infusion over an extended period, the spontaneous deamination of adenine to hypoxanthine, together with the inclusion of allopurinol to inhibit its conversion to 2,8 dihydroxyadenine, would mitigate against the toxicity of adenine.

In this regard, allopurinol may have benefits additional to preventing the conversion of adenine to 2,8 dihydroxyadenine; by similarly preventing the conversion of hypoxanthine to the non-salvageable xanthine (Fig. 1), allopurinol would simultaneously allow greater availability of endogenous hypoxanthine for the salvage pathway. Sparing of purines during cerebral ischemia by allopurinol or the active metabolite oxypurinol has indeed been observed, with functional benefits $[112,113]$. In addition to purine-sparing actions of xanthine oxidase inhibition, such inhibitors would also prevent the production of reactive oxygen species created by the subsequent metabolism of xanthine which yields hydrogen peroxide. This double benefit of allopurinol is being tested in the context of the hypoxic/ischemic neonate to whom allopurinol can be administered via the maternal/placental circulation [114].

\section{Penetration into the Brain}

Since ribose, adenine and indeed allopurinol (eg for the treatment of gout) are all in use in man, to what extent might they enter the brain via the systemic circulation? Ribose is a peculiar compound in that it is extremely permeable through lipid membranes, a fact that may have permitted the emergence of the ribose-based RNA world [115, 116]. Its rapid uptake into brain was demonstrated following tracking of radiolabelled ribose [117]. In contrast to the liver $[117,118]$, ribose taken up into the brain is not converted to glucose [117]. Whether its uptake occurs by diffusion $[119,120]$ or via a transport mechanism [121] is not clear. Uptake may occur via a glucose transporter since it partially interferes with glucose transport [122], potentially GLUT2 [118], which is found in brain [123]. Indeed other members of the SLC2 glucose transporter family may, in addition to glucose, transport pentose sugars [124, 125].

The evidence for adenine uptake into the brain is clearer [126] and likely occurs via the equilibrative nucleoside transporters (ENTs; SLC29). ENT1 and ENT2 have a fairly ubiquitous cell surface expression and are capable of mediating adenine (and hypoxanthine) transport across the blood brain barrier [126-129]. It is also likely that allopurinol enters the brain in this way, given its closely related structure to hypoxanthine (Fig. 1), and indeed the uptake of adenine, hypoxanthine and allopurinol interfere with each other [130]. In contrast, access to the brain of creatine is severely limited by the absence of creatine transporters on the astrocytic endfeet that envelop cerebral blood vessels and thereby requiring extensive pre-treatment to demonstrate benefits in animal models of brain injury [131].

\section{Therapeutic Potential of RibAde-Based Therapy: The Proof of Concept is in the Stroke Model}

These considerations were recently put the test in an in vivo model of stroke. Rats underwent a transient, $60 \mathrm{~min}$, filament occlusion of the middle cerebral artery and, upon reperfusion, were administered an intravenous $6 \mathrm{~h}$ infusion of either saline, RibAde (200 and $10 \mathrm{mg} / \mathrm{kg}$, respectively) or RibAde plus an intraperitoneal injection of the xanthine oxidase inhibitor, allopurinol, (10 mg/kg; RibAdeAll). MRI scans were taken prior to infusion and at day 7 . Neurological 

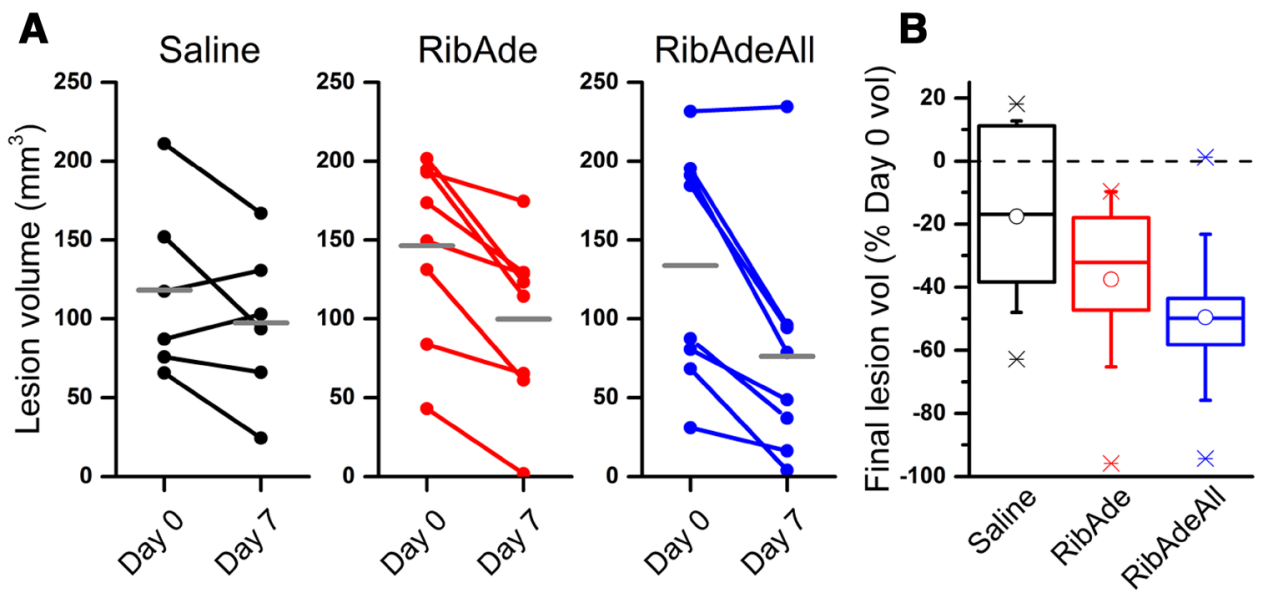

Fig. 7 RibAde and RibAdeAll (RibAde plus allopurinol) showed a trend towards reduced lesion volume in a pre-clinical model of stroke. A Individual paired measurements of lesion volume at Day 0 and Day 7 in the three experimental groups of animals showing a consistent trend for substantial lesion shrinkage in the RibAde $(n=8)$ and RibAdeAll $(n=8)$ groups compared to saline controls $(n=6)$. Grey hori-
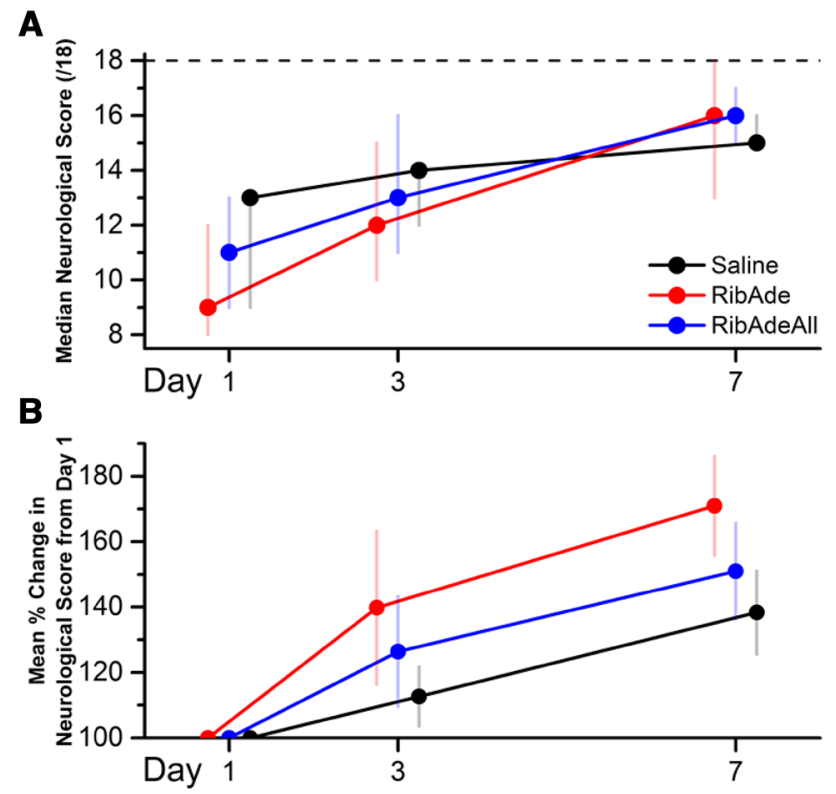

zontal bars show mean lesion volume by day. B Change in lesion volume between Days 0 and 7 normalized to lesion size on Day 0. Mean lesion size (open circles) decreased by $18 \%$ in the saline group, $38 \%$ in the RibAde group and 50\% in the RibAdeAll group. Horizontal line, median; box $25-75 \%$ range; whiskers, $\pm 1 \mathrm{SD} ; \mathrm{X}$, min and max values. Adapted from [132]

testing occurred at days 1, 3 and 7. RibAde- and RibAdeAlltreated animals displayed a strong tendency towards reduced lesion volumes compared to saline-treated rats (Fig. 7), and evidence of accelerated neurological recovery (Fig. 8). This study [132] was underpowered and did not achieve statistical significance, but does provide valuable proof of concept information in that these doses of ribose, adenine and allopurinol are tolerated, do not cause kidney damage and may indeed reduce brain damage and improve functional recovery after injury. Subsequent studies would need to be adequately powered (we estimate 13 animals per group) and, as per all preclinical stroke work, should adhere to appropriate STAIR [133], ARRIVE [134] and the recent IMPROVE [135] guidelines. ${ }^{1}$

\section{Conclusions}

The ATP content of brain slices can be restored to values recorded in vivo. This has immediate consequences in increasing the cellular reservoir of the neuromodulator

Fig. 8 RibAde and RibAdeAll treatment resulted in a tendency towards improved neurological outcome after stroke. All animals scored the maximum value of 18 prior to transient middle cerebral artery occlusion (tMCAO; dashed line on A). A Median neurological scores (from minimum of 3 to maximum of 18; dashed line) per group on Day 1, 3 and 7 after induction of stroke $(n=8$ in RibAde and RibAdeAll groups and $n=6$ in saline group). Bars indicate the 1st and 3rd quartiles for each data point. Median and quartile values are rounded to nearest whole number. Data points for each group have been offset for clarity. B Mean neurological scores $( \pm$ SEM) for each day normalised to Day 1 revealed a trend to faster recovery despite larger initial lesions in the treatment groups, consistent with the greater reduction in lesion size (Fig. 7). Data points for each group have been offset for clarity. Adapted from [132] adenosine with, as we have shown, quite pronounced effeicts on synaptic transmission and plasticity under both physiological and pathological conditions. Wider adoption of RibAde in slice incubation media might reveal other effects of increasing tissue ATP levels, for example in an enhancement

\footnotetext{
${ }^{1}$ STAIR-Stroke Therapy Academic Industry Roundtable; ARRIVE-Animal Research: Reporting of In Vivo Experiments; IMPROVE - Ischaemia Models: Procedural Refinements Of in Vivo Experiments.
} 
in the size of synaptic events mediated by the release of ATP and activation of ionotropic P2X receptors, of greater modulatory actions of GPCR P2Y receptors, and indeed on adenosine receptors beyond the inhibitory $\mathrm{A}_{1}$ receptors whose actions we have studied. Cellular biochemistry may also be influenced in terms of appropriate utilization of cellular energy sources, the balance between glycolysis and oxidative phosphorylation, andthe kinetics and extent of cellular reactions, such as phosphorylation, that require ATP.

In terms of what RibAde-based approaches may mean for the injured brain remains to be seen, but the pilot data in the preclinical stroke model are encouraging. The loss of substrates for the purine salvage pathway after the cerebral ischemia and trauma associated with brain slice preparation has strong parallels with what happens during these conditions in humans and experimental animals. Accordingly, post-injury infusion of RibAde may be of value in restoring cerebral ATP levels in tissue peripheral to the injury, but vulnerable to expansion of the damaged area. This penumbral tissue is potentially salvageable and the focus of existing therapies such as thrombectomy or thrombolysis for ischemic stroke, and the lowering of intracranial pressure after traumatic brain injury. Restoring ATP in these regions would: (1) facilitate better maintenance of membrane potential in the face of depolarising waves (spreading depression/ depolarizations, peri-infarct depolarisations) commonly associated with brain injury; (2) allow cells to activate reparative mechanisms, such as protein synthesis, which is inhibited after injury, and (3) promote the release of greater amounts of adenosine with its inhibitory, anticonvulsant influence on neuronal activity, and its vasodilatory actions on the cerebral vasculature. These actions of adenosine may mitigate against the seizure activity frequently seen after brain injury, and may prevent entry into an epileptogenic state, a common sequela of severe brain injury; improved blood flow will deliver oxygen and glucose to help protect and repair vulnerable brain tissue.

As speed is of the essence in the treatment of brain injury, one could imagine civilian or military paramedics being equipped with saline packs containing RibAde, with for example, allopurinol (RibAdeAll), in order that treatment may be initiated at the point of injury. Given the increase in both civilian and military head injury victims, who are generally in mid-life or younger, and the ageing population, with the associated risk of stroke, such an approach may be of value in reducing the consequences of the brain injury and the individual and familial suffering that it brings, not to mention the huge societal costs of brain injury in terms of treatment, care and lost earnings.

Acknowledgements I am grateful to Dr Martin Lochner for providing a ChemDraw template for some of the structures used in Fig. 1 and which formed the basis for the structures shown. Any errors are solely the author's. I am also grateful to Dr Lilya Andrianova for translating the paper by Belen'kii et al. [50] from the original Russian, and to Dr Mark Wall for reading a draft of this review. This work was supported by funding from The Wellcome Trust, Research into Aging, The University of Warwick Alumnus Fund, BBSRC, The Rosetrees Trust.

\section{Compliance with Ethical Standards}

Conflict of interest The author is a Non-Executive Director of Sarissa Biomedical Ltd, the company that manufactures the microelectrode biosensors used in Figs. 5 and 6, and its subsidiary, Sarissa Diagnostics, which is developing purine-based sensors for the diagnosis of stroke.

Open Access This article is distributed under the terms of the Creative Commons Attribution 4.0 International License (http://creativecommons.org/licenses/by/4.0/), which permits unrestricted use, distribution, and reproduction in any medium, provided you give appropriate credit to the original author(s) and the source, provide a link to the Creative Commons license, and indicate if changes were made.

\section{References}

1. Collingridge GL (1995) The brain slice preparation: a tribute to the pioneer Henry McIlwain. J Neurosci Methods 59:5-9

2. Mcllwain H (1950) Brain metabolism and activity. Br Med Bull 6(4):301-303

3. McIlwain H, Buchel L, Chesire JD (1951) The inorganic phosphate and phosphocreatine of brain especially during metabolism in vitro. Biochem J 48:12-20

4. Thomas J (1956) The composition of isolated cerebral tissues; creatine. Biochem J 64(2):335-339

5. Thomas J, McIlwain H (1956) Chloride content and metabolism of cerebral tissues in fluids low in chlorides. J Neurochem $1(1): 1-7$

6. McIlwain H, Tresize MA (1956) The glucose, glycogen and aerobic glycolysis of isolated cerebral tissues. Biochem $\mathrm{J}$ 63(2):250-257

7. Bell JL, McIlwain H, Thomas J (1956) The composition of isolated cerebral tissues; ascorbic acid and cozymase. Biochem $\mathrm{J}$ 64(2):332-335

8. Kerr SE (1942) Studies on the phosphorus compounds of brain: III. Determinations of adenosine triphosphate and its decomposition products in fresh and autolyzed dog brain. J Biol Chem 145:10

9. Gerlach E, Doring HJ, Fleckenstein A (1958) Paper chromatographic studies on adenine and guanine nucleotides as well as other acid-soluble phosphorus compounds of the brain in anesthesia, ischemia and in relation to the technic of tissue extraction. Pflugers Arch Gesamte Physiol Menschen Tiere 266(3):266-291

10. Harris JJ, Jolivet R, Attwell D (2012) Synaptic energy use and supply. Neuron 75(5):762-777

11. Lowry OH, Passonneau JV, Hasselberger FX, Schulz DW (1964) Effect of ischemia on known substrates and cofactors of the glycolytic pathway in brain. J Biol Chem 239:18-30

12. Bingmann D, Kolde G (1982) PO2-profiles in hippocampal slices of the guinea pig. Exp Brain Res 48(1):89-96

13. Fujii T, Baumgartl H, Lubbers DW (1982) Limiting section thickness of guinea pig olfactory cortical slices studied from tissue pO2 values and electrical activities. Pflugers Arch 393(1):83-87

14. Jiang C, Agulian S, Haddad GG (1991) $\mathrm{O}_{2}$ tension in adult and neonatal brain slices under several experimental conditions. Brain Res 568(1-2):159-164 
15. Moore KA, Nicoll RA, Schmitz D (2003) Adenosine gates synaptic plasticity at hippocampal mossy fiber synapses. Proc Natl Acad Sci USA 100(24):14397-14402

16. Kukley M, Schwan M, Fredholm BB, Dietrich D (2005) The role of extracellular adenosine in regulating mossy fiber synaptic plasticity. J Neurosci 25(11):2832-2837

17. Hossmann KA (2008) Cerebral ischemia: models, methods and outcomes. Neuropharmacology 55(3):257-270

18. Engl E, Attwell D (2015) Non-signalling energy use in the brain. J Physiol 593(16):3417-3429. doi:10.1113/jphysiol.2014.282517

19. Sweatt JD (2016) Neural plasticity and behavior-sixty years of conceptual advances. J Neurochem 139(Suppl 2):179-199. doi:10.1111/jnc. 13580

20. Jacobson KA, Muller CE (2016) Medicinal chemistry of adenosine, P2Y and P2X receptors. Neuropharmacology 104:31-49. doi:10.1016/j.neuropharm.2015.12.001

21. Amato S, Man HY (2011) Bioenergy sensing in the brain: the role of AMP-activated protein kinase in neuronal metabolism, development and neurological diseases. Cell Cycle 10(20):34523460. doi: $10.4161 /$ cc. 10.20 .17953

22. Hardie DG (2015) AMPK: positive and negative regulation, and its role in whole-body energy homeostasis. Curr Opin Cell Biol 33:1-7. doi:10.1016/j.ceb.2014.09.004

23. zur Nedden S, Hawley SA, Pentland N, Hardie DG, Doney AS, Frenguelli BG (2011) Intracellular ATP influences synaptic plasticity in area CA1 of rat hippocampus via metabolism to adenosine and activity-dependent activation of adenosine A1 receptors. J Neurosci 31:6221-6234

24. Thomas J (1957) The composition of isolated cerebral tissue; purines. Biochem J 66(4):655-658

25. Newman GC, Hospod FE, Trowbridge SD, Motwani S, Liu Y (1998) Restoring adenine nucleotides in a brain slice model of cerebral reperfusion. J Cereb Blood Flow Metab 18:675-685

26. Pedata F, Dettori I, Coppi E, Melani A, Fusco I, Corradetti R, Pugliese AM (2016) Purinergic signalling in brain ischemia. Neuropharmacology 104:105-130. doi:10.1016/j. neuropharm.2015.11.007

27. Ribeiro FF, Xapelli S, Miranda-Lourenco C, Tanqueiro SR, Fonseca-Gomes J, Diogenes MJ, Ribeiro JA, Sebastiao AM (2016) Purine nucleosides in neuroregeneration and neuroprotection. Neuropharmacology 104:226-242. doi:10.1016/j. neuropharm.2015.11.006

28. Dennis SH, Jaafari N, Cimarosti H, Hanley JG, Henley JM, Mellor JR (2011) Oxygen/glucose deprivation induces a reduction in synaptic AMPA receptors on hippocampal CA3 neurons mediated by mGluR1 and adenosine A3 receptors. J Neurosci 31(33):11941-11952. doi:10.1523/JNEUROSCI.1183-11.2011

29. Stoddart LA, Vernall AJ, Briddon SJ, Kellam B, Hill SJ (2015) Direct visualisation of internalization of the adenosine A3 receptor and localization with arrestin3 using a fluorescent agonist. Neuropharmacology 98:68-77. doi:10.1016/j. neuropharm.2015.04.013

30. Stockwell J, Chen Z, Niazi M, Nosib S, Cayabyab FS (2016) Protein phosphatase role in adenosine A1 receptor-induced AMPA receptor trafficking and rat hippocampal neuronal damage in hypoxia/reperfusion injury. Neuropharmacology 102:254-265. doi:10.1016/j.neuropharm.2015.11.018

31. Chen Z, Stockwell J, Cayabyab FS (2016) Adenosine A1 receptor-mediated endocytosis of AMPA receptors contributes to impairments in long-term potentiation (LTP) in the middleaged rat hippocampus. Neurochem Res 41(5):1085-1097. doi:10.1007/s11064-015-1799-3

32. Baines AE, Corrêa SA, Irving AJ, Frenguelli BG (2011) Differential trafficking of adenosine receptors in hippocampal neurons monitored using GFP- and super-ecliptic pHluorin-tagged receptors. Neuropharmacology 61:1-11
33. Dale N, Frenguelli BG (2009) Release of adenosine and ATP during ischemia and epilepsy. Curr Neuropharmacol 7(3):160-179

34. Etherington LA, Patterson GE, Meechan L, Boison D, Irving AJ, Dale N, Frenguelli BG (2009) Astrocytic adenosine kinase regulates basal synaptic adenosine levels and seizure activity but not activity-dependent adenosine release in the hippocampus. Neuropharmacology 56(2):429-437

35. Diogenes MJ, Neves-Tome R, Fucile S, Martinello K, Scianni M, Theofilas P, Lopatar J, Ribeiro JA, Maggi L, Frenguelli BG, Limatola C, Boison D, Sebastiao AM (2014) Homeostatic control of synaptic activity by endogenous adenosine is mediated by adenosine kinase. Cereb Cortex 24:67-80

36. Boison D (2016) Adenosinergic signaling in epilepsy. Neuropharmacology 104:131-139. doi:10.1016/j.neuropharm.2015.08.046

37. Coffman JD, Lewis FB, Gregg DE (1960) Effect of prolonged periods of anoxia on atrioventricular conduction and cardiac muscle. Circ Res 8:649-659

38. Benson ES, Evans GT, Hallaway BE, Phibbs C, Freier EF (1961) Myocardial creatine phosphate and nucleotides in aoxic cardiac arrest and recovery. Am J Physiol 201:678-693

39. Goldthwait DA (1957) Mechanisms of synthesis of purine nucleotides in heart muscle extracts. J Clin Invest 36(11):1572-1578. doi:10.1172/JCI103555

40. Fox AC, Reed GE, Meilman H, Silk BB (1979) Release of nucleosides from canine and human hearts as an index of prior ischemia. Am J Cardiol 43(1):52-58

41. Drury AN, Szent-Gyorgyi A (1929) The physiological activity of adenine compounds with especial reference to their action upon the mammalian heart. J Physiol 68(3):213-237

42. Zimmer HG (1998) Significance of the 5-phosphoribosyl-1-pyrophosphate pool for cardiac purine and pyrimidine nucleotide synthesis: studies with ribose, adenine, inosine, and orotic acid in rats. Cardiovasc Drugs Ther 12(Suppl 2):179-187

43. Ward HB, Wang T, Einzig S, Bianco RW, Foker JE (1983) Prevention of ATP catabolism during myocardial ischemia: a preliminary report. J Surg Res 34(4):292-297

44. Ward HB, St Cyr JA, Cogordan JA, Alyono D, Bianco RW, Kriett JM, Foker JE (1984) Recovery of adenine nucleotide levels after global myocardial ischemia in dogs. Surgery 96(2):248-255

45. Zimmer HG, Gerlach E (1978) Stimulation of myocardial adenine nucleotide biosynthesis by pentoses and pentitols. Pflugers Arch 376(3):223-227

46. Zimmer HG, Schneider A (1991) Nucleotide precursors modify the effects of isoproterenol. Studies on heart function and cardiac adenine nucleotide content in intact rats. Circ Res 69(6):1575-1582

47. Foker JE (1986) Method for stimulating recovery from ischemia employing ribose and adenine USA Patent

48. Bayram M, St Cyr JA, Abraham WT (2015) D-ribose aids heart failure patients with preserved ejection fraction and diastolic dysfunction: a pilot study. Ther Adv Cardiovasc Dis 9(3):56-65. doi: $10.1177 / 1753944715572752$

49. Cicero AF, Colletti A (2017) Nutraceuticals and dietary supplements to improve quality of life and outcomes in heart failure patients. Curr Pharm Des 23:1265-1272

50. Belen'kii EE, Pogosova AV, Tunitskaia TA, Borisova TA (1966) Effect of orotic acid and purinor on the myocardium in compensatory hypertrophy and hyperfunction of heart, caused by experimental stenosis of aorta [In Russian]. Farmakol Toksikol 29(6):685-688

51. Lipton P, Robacker K (1982) Adenosine may cause an early inhibition of synaptic transmission during anoxia. Soc Neurosci Abstr 8:283

52. Lloyd HG, Spence I, Johnston GA (1988) Involvement of adenosine in synaptic depression induced by a brief period of hypoxia in isolated spinal cord of neonatal rat. Brain Res 462(2):391-395 
53. Fowler JC (1989) Adenosine antagonists delay hypoxia-induced depressions of neuronal activity in hippocampal brain slice. Brain Res 490:378-384

54. Fowler JC (1990) Adenosine antagonists alter the synaptic response to in vitro ischemia in the rat hippocampus. Brain Res 509:331-334

55. Pearson T, Damian K, Lynas R, Frenguelli BG (2006) Sustained elevation of extracellular adenosine and activation of A1 receptors underlie the post-ischaemic inhibition of neuronal function in rat hippocampus in vitro. J Neurochem 97:1357-1368

56. Gervitz LM, Lutherer LO, Davies DG, Pirch JH, Fowler JC (2001) Adenosine induces initial hypoxic-ischemic depression of synaptic transmission in the rat hippocampus in vivo. Am J Physiol Regul Integr Comp Physiol 280:R639-R645

57. Ilie A, Ciocan D, Zagrean AM, Nita DA, Zagrean L, Moldovan M (2006) Endogenous activation of adenosine A(1) receptors accelerates ischemic suppression of spontaneous electrocortical activity. J Neurophysiol 96(5):2809-2814

58. Constantinescu AO, Ilie A, Ciocan D, Zagrean AM, Zagrean L, Moldovan M (2011) Endogenous adenosine A1 receptor activation underlies the transient post-ischemic rhythmic delta EEG activity. Clin Neurophysiol 122(6):1117-1126. doi:10.1016/j. clinph.2010.09.015

59. Pearson T, Nuritova F, Caldwell D, Dale N, Frenguelli BG (2001) A depletable pool of adenosine in area CA1 of the rat hippocampus. J Neurosci 21:2298-2307

60. Valtysson J, Persson L, Hillered L (1998) Extracellular ischaemia markers in repeated global ischaemia and secondary hypoxaemia monitored by microdialysis in rat brain. Acta Neurochir(Wien) 140:387-395

61. Dux E, Fastbom J, Ungerstedt U, Rudolphi K, Fredholm BB (1990) Protective effect of adenosine and a novel xanthine derivative propentofylline on the cell damage after bilateral carotid occlusion in the gerbil hippocampus. Brain Res 516:248-256

62. Ilie A, Spulber S, Avramescu S, Nita DA, Zagrean AM, Zagrean L, Moldovan M (2006) Delayed ischemic electrocortical suppression during rapid repeated cerebral ischemia and kainate-induced seizures in rat. Eur J Neurosci 23(8):2135-2144

63. Kirino T (2002) Ischemic tolerance. J Cereb Blood Flow Metab 22(11):1283-1296

64. Levin HS, Diaz-Arrastia RR (2015) Diagnosis, prognosis, and clinical management of mild traumatic brain injury. Lancet Neurol 14(5):506-517. doi:10.1016/S1474-4422(15)00002-2

65. Pearson T, Currie AJ, Etherington LA, Gadalla AE, Damian K, Llaudet E, Dale N, Frenguelli BG (2003) Plasticity of purine release during cerebral ischemia: clinical implications? J Cell Mol Med. 7(4):362-375

66. Gerlach E, Marko P, Zimmer HG, Pechan I, Trendelenburg C (1971) Different response of adenine nucleotide synthesis de novo in kidney and brain during aerobic recovery from anoxia and ischemia. Experientia 27:876-878

67. Barsotti C, Tozzi MG, Ipata PL (2002) Purine and pyrimidine salvage in whole rat brain. Utilization of ATP-derived ribose1-phosphate and 5-phosphoribosyl-1-pyrophosphate generated in experiments with dialyzed cell-free extracts. J Biol Chem 277(12):9865-9869

68. Ipata PL, Camici M, Micheli V, Tozz MG (2011) Metabolic network of nucleosides in the brain. Curr Top Med Chem 11(8):909-922

69. Blatherwick EQ, Svensson CI, Frenguelli BG, Scrivens JH (2013) Localisation of adenine nucleotides in heat-stabilised mouse brains using ion mobility enabled MALDI imaging. Int $\mathbf{J}$ Mass Spectrom 345:19-27. doi:10.1016/j.ijms.2013.02.004

70. Liu H, Chen R, Wang J, Chen S, Xiong C, Wang J, Hou J, He Q, Zhang N, Nie Z, Mao L (2014) 1,5-Diaminonaphthalene hydrochloride assisted laser desorption/ionization mass spectrometry imaging of small molecules in tissues following focal cerebral ischemia. Anal Chem 86(20):10114-10121. doi:10.1021/ac5034566

71. Mulder IA, Esteve C, Wermer MJ, Hoehn M, Tolner EA, van den Maagdenberg AM, McDonnell LA (2016) Funnel-freezing versus heat-stabilization for the visualization of metabolites by mass spectrometry imaging in a mouse stroke model. Proteomics 16(11-12):1652-1659. doi:10.1002/pmic.201500402

72. Weigand MA, Michel A, Eckstein HH, Martin E, Bardenheuer HJ (1999) Adenosine: a sensitive indicator of cerebral ischemia during carotid endarterectomy. Anesthesiology 91:414-421

73. Vagnozzi R, Signoretti S, Cristofori L, Alessandrini F, Floris R, Isgro E, Ria A, Marziale S, Zoccatelli G, Tavazzi B, Del BF, Sorge R, Broglio SP, McIntosh TK, Lazzarino G (2010) Assessment of metabolic brain damage and recovery following mild traumatic brain injury: a multicentre, proton magnetic resonance spectroscopic study in concussed patients. Brain 133(11):3232-3242

74. Whittingham TS, Lust WD, Passonneau JV (1984) An in vitro mdel of ischemia: Metabolic and electrical alterations in the hippocampal slice. J Neurosci 4(3):793-802

75. Reid KH, Edmonds HL, Schurr A, Tseng MT, West CA (1988) Pitfalls in the use of brain slices. Prog Neurobiol 31:1-18

76. Atkinson DE (1968) The energy charge of the adenylate pool as a regulatory parameter. Interaction with feedback modifiers. BioChemistry 7(11):4030-4034

77. zur Nedden S, Eason R, Doney AS, Frenguelli BG (2009) An ion-pair reversed-phase HPLC method for determination of fresh tissue adenine nucleotides avoiding freeze-thaw degradation of ATP. Anal Biochem 388:108-114

78. Moriwaki Y, Yamamoto T, Higashino K (1999) Enzymes involved in purine metabolism-a review of histochemical localization and functional implications. Histol Histopathol 14:1321-1340

79. Maliekal P, Sokolova T, Vertommen D, Veiga-da-Cunha M, Van Schaftingen E (2007) Molecular identification of mammalian phosphopentomutase and glucose-1,6-bisphosphate synthase, two members of the alpha-D-phosphohexomutase family. J Biol Chem 282(44):31844-31851. doi:10.1074/jbc. M706818200

80. Zhang Y, Chen K, Sloan SA, Bennett ML, Scholze AR, O'Keeffe S, Phatnani HP, Guarnieri P, Caneda C, Ruderisch N, Deng S, Liddelow SA, Zhang C, Daneman R, Maniatis T, Barres BA, Wu JQ (2014) An RNA-sequencing transcriptome and splicing database of glia, neurons, and vascular cells of the cerebral cortex. J Neurosci 34(36):11929-11947. doi:10.1523/ JNEUROSCI.1860-14.2014

81. Fu R, Ceballos-Picot I, Torres RJ, Larovere LE, Yamada Y, Nguyen KV, Hegde M, Visser JE, Schretlen DJ, Nyhan WL, Puig JG, O’Neill PJ, Jinnah HA, Lesch-Nyhan Disease International Study G (2014) Genotype-phenotype correlations in neurogenetics: Lesch-Nyhan disease as a model disorder. Brain 137 (Pt 5):1282-1303. doi:10.1093/brain/awt202

82. Panayiotou C, Solaroli N, Karlsson A (2014) The many isoforms of human adenylate kinases. Int J Biochem Cell Biol 49:75-83. doi:10.1016/j.biocel.2014.01.014

83. Kasthuri N, Hayworth KJ, Berger DR, Schalek RL, Conchello JA, Knowles-Barley S, Lee D, Vazquez-Reina A, Kaynig V, Jones TR, Roberts M, Morgan JL, Tapia JC, Seung HS, Roncal WG, Vogelstein JT, Burns R, Sussman DL, Priebe CE, Pfister H, Lichtman JW (2015) Saturated reconstruction of a volume of neocortex. Cell 162(3):648-661. doi:10.1016/j. cell.2015.06.054

84. MacAskill AF, Kittler JT (2010) Control of mitochondrial transport and localization in neurons. Trends Cell Biol 20(2):102112. doi: $10.1016 /$ j.tcb.2009.11.002 
85. Mitchell JB, Lupica CR, Dunwiddie TV (1993) Activitydependent release of endogenous adenosine modulates synaptic responses in the rat hippocampus. J Neurosci 13:3439-3447

86. Brager DH, Thompson SM (2003) Activity-dependent release of adenosine contributes to short-term depression at CA3-CA1 synapses in rat hippocampus. J Neurophysiol 89(1):22-26

87. Lovatt D, Xu Q, Liu W, Takano T, Smith NA, Schnermann J, Tieu K, Nedergaard M (2012) Neuronal adenosine release, and not astrocytic ATP release, mediates feedback inhibition of excitatory activity. Proc Natl Acad Sci USA 109:6265-6270

88. Sims RE, Dale N (2014) Activity-dependent adenosine release may be linked to activation of $\mathrm{Na}(+)-\mathrm{K}(+)$ ATPase: an in vitro rat study. PLoS ONE 9(1):e87481

89. Siklos L, Kuhnt U, Parducz A, Szerdahelyi P (1997) Intracellular calcium redistribution accompanies changes in total tissue $\mathrm{Na}+$ $\mathrm{K}+$ and water during the first two hours of in vitro incubation of hippocampal slices. Neuroscience 79(4):1013-1022

90. Bakthavachalam P, Shanmugam PS (2017) Mitochondrial dysfunction-Silent killer in cerebral ischemia. J Neurol Sci 375:417-423. doi:10.1016/j.jns.2017.02.043

91. Chinopoulos C (2011) Mitochondrial consumption of cytosolic ATP: not so fast. FEBS Lett 585(9):1255-1259. doi:10.1016/j. febslet.2011.04.004

92. Chinopoulos C, Adam-Vizi V (2010) Mitochondria as ATP consumers in cellular pathology. Biochim Biophys Acta 1802(1):221-227. doi:10.1016/j.bbadis.2009.08.008

93. Dienel GA (2014) Lactate shuttling and lactate use as fuel after traumatic brain injury: metabolic considerations. J Cereb Blood Flow Metab 34(11):1736-1748. doi:10.1038/jcbfm.2014.153

94. Prins ML, Matsumoto JH (2014) The collective therapeutic potential of cerebral ketone metabolism in traumatic brain injury. J Lipid Res 55(12):2450-2457. doi:10.1194/jlr.R046706

95. Kanatani T, Mizuno K, Okada Y (1995) Effects of glycolytic metabolites on preservation of high energy phosphate level and synaptic transmission in the granule cells of guinea pig hippocampal slices. Experientia 51(3):213-216

96. Gilbert E, Tang JM, Ludvig N, Bergold PJ (2006) Elevated lactate suppresses neuronal firing in vivo and inhibits glucose metabolism in hippocampal slice cultures. Brain Res 1117(1):213-223. doi:10.1016/j.brainres.2006.07.107

97. Arakawa T, Goto T, Okada Y (1991) Effect of ketone body (D-3-hydroxybutyrate) on neural activity and energy metabolism in hippocampal slices of the adult guinea pig. Neurosci Lett 130(1):53-56

98. zur Nedden S, Doney AS, Frenguelli BG (2014) Modulation of intracellular ATP determines adenosine release and functional outcome in response to metabolic stress in rat hippocampal slices and cerebellar granule cells. J Neurochem 128:111-124

99. Wall MJ, Wigmore G, Lopatar J, Frenguelli BG, Dale N (2008) The novel NTPDase inhibitor sodium polyoxotungstate (POM-1) inhibits ATP breakdown but also blocks central synaptic transmission, an action independent of NTPDase inhibition. Neuropharmacology 55(7):1251-1258

100. Pull I, McIlwain H (1972) Metabolism of (14 C)adenine and derivatives by cerebral tissues, superfused and electrically stimulated. Biochem J 126(4):965-973

101. Arai A, Kessler M, Lynch G (1990) The effects of adenosine on the development of long-term potentiation. Neurosci Lett 119:41-44

102. Balestrino M, Sarocchi M, Adriano E, Spallarossa P (2016) Potential of creatine or phosphocreatine supplementation in cerebrovascular disease and in ischemic heart disease. Amino Acids 48(8):1955-1967. doi:10.1007/s00726-016-2173-8

103. Hall J, Frenguelli BG (2015) Modulation of intracellular ATP influences seizure activity via the activity-dependent release of adenosine. Society for Neuroscience Annual Meeting 766.06:C59
104. Shecterle LM, Terry KR, St Cyr JA (2010) The patented uses of D-ribose in cardiovascular diseases. Recent Pat Cardiovasc Drug Discov 5(2):138-142

105. Gross M, Zöllner N (1991) Serum levels of glucose, insulin, and C-peptide during long-term D-ribose administration in man. Klin Wochenschr 69(1):31-36

106. Jauch-Chara K, Oltmanns KM (2014) Glycemic control after brain injury: boon and bane for the brain. Neuroscience 283:202-209. doi:10.1016/j.neuroscience.2014.04.059

107. Hess JR (2006) An update on solutions for red cell storage. Vox Sang 91(1):13-19. doi:10.1111/j.1423-0410.2006.00778.x

108. Bollee G, Harambat J, Bensman A, Knebelmann B, Daudon M, Ceballos-Picot I (2012) Adenine phosphoribosyltransferase deficiency. Clin J Am Soc Nephrol 7(9):1521-1527. doi:10.2215/CJN.02320312

109. Warner WL (1977) Toxicology and pharmacology of adenine in animals and man. Transfusion 17(4):326-332

110. Siegel DC, Reed PC, Fresquez V, Cochin A, Moss GS (1971) Renal effects of massive infusions of adenine during resuscitation from hemorrhagic shock in the baboon. Ann Surg 174(6):932-938

111. Falk JS, Lindblad GT, Westman BJ (1972) Histopathological studies on kidneys from patients treated with large amounts of blood preserved with ACD-adenine. Transfusion 12(6):376-381

112. Phillis JW (1989) Oxypurinol attenuates ischemia-induced hippocampal damage in the gerbil. Brain Res Bull 23:467-470

113. Phillis JW, Perkins LM, Smith-Barbour M, O'Regan MH (1995) Oxypurinol-enhanced postischemic recovery of the rat brain involves preservation of adenine nucleotides. J Neurochem 64:2177-2184

114. Juul SE, Ferriero DM (2014) Pharmacologic neuroprotective strategies in neonatal brain injury. Clin Perinatol 41(1):119-131. doi:10.1016/j.clp.2013.09.004

115. Sacerdote MG, Szostak JW (2005) Semipermeable lipid bilayers exhibit diastereoselectivity favoring ribose. Proc Natl Acad Sci USA 102(17):6004-6008

116. Wei C, Pohorille A (2013) Permeation of aldopentoses and nucleosides through fatty acid and phospholipid membranes: implications to the origins of life. Astrobiology 13(2):177-188. doi:10.1089/ast.2012.0901

117. Gaitonde MK, Arnfred T (1971) Metabolism of D-[U-14C]ribose in rat tissues. J Neurochem 18(10):1971-1987

118. Clark PM, Flores G, Evdokimov NM, McCracken MN, Chai T, Nair-Gill E, O’Mahony F, Beaven SW, Faull KF, Phelps ME, Jung ME, Witte ON (2014) Positron emission tomography probe demonstrates a striking concentration of ribose salvage in the liver. Proc Natl Acad Sci USA 111(28):E2866-E2874. doi:10.1073/pnas.1410326111

119. Agnew WF, Crone C (1967) Permeability of brain capillaries to xexoses and pentoses in the rabbit. Acta Physiol Scand 70:168-175

120. Joanny P, Corriol J, Hillman H (1969) Uptake of monosaccharides by guinea-pig cerebral-cortex slices. Biochem $\mathrm{J}$ 112(3):367-371

121. Prather JW, Wright EM (1970) Molecular and kinetic parameters of sugar transport across the frog choroid plexus. J Membr Biol 2:150-172

122. Betz AL, Drewes LR, Gilboe DD (1975) Inhibition of glucose transport into brain by phlorizin, phloretin and glucose analogues. BiochimBiophysActa 406(4):505-515

123. Patching SG (2017) Glucose transporters at the blood-brain barrier: function, regulation and gateways for drug delivery. Mol Neurobiol 54(2):1046-1077. doi:10.1007/s12035-015-9672-6

124. Cura AJ, Carruthers A (2012) Role of monosaccharide transport proteins in carbohydrate assimilation, distribution, metabolism, 
and homeostasis. Compr Physiol 2(2):863-914. doi:10.1002/ cphy.c110024

125. Mueckler M, Thorens B (2013) The SLC2 (GLUT) family of membrane transporters. Mol Aspects Med 34(2-3):121-138. doi:10.1016/j.mam.2012.07.001

126. Cornford EM, Oldendorf WH (1975) Independent blood-brain barrier transport systems for nucleic acid precursors. Biochim Biophys Acta 394(2):211-219

127. Parkinson FE, Damaraju VL, Graham K, Yao SY, Baldwin SA, Cass CE, Young JD (2011) Molecular biology of nucleoside transporters and their distributions and functions in the brain. Curr Top Med Chem 11(8):948-972

128. Young JD, Yao SY, Baldwin JM, Cass CE, Baldwin SA (2013) The human concentrative and equilibrative nucleoside transporter families, SLC28 and SLC29. Mol Aspects Med 34(23):529-547. doi:10.1016/j.mam.2012.05.007

129. Boswell-Casteel RC, Hays FA (2017) Equilibrative nucleoside transporters-A review. Nucleosides Nucleotides Nucleic Acids 36(1):7-30. doi:10.1080/15257770.2016.1210805

130. Betz AL (1985) Identification of hypoxanthine transport and xanthine oxidase activity in brain capillaries. J Neurochem 44(2):574-579

131. Perasso L, Spallarossa $P$, Gandolfo C, Ruggeri P, Balestrino M (2013) Therapeutic use of creatine in brain or heart ischemia: available data and future perspectives. Med Res Rev 33(2):336363. doi:10.1002/med.20255

132. Faller KM, Leach J, Johnston P, Holmes WM, Macrae IM, Frenguelli BG (2017) Proof of concept and feasibility studies examining the influence of combination ribose, adenine and allopurinol treatment on stroke outcome in the rat. Brain Neurosci Adv. doi: $10.1177 / 2398212817717112$

133. Fisher M, Feuerstein G, Howells DW, Hurn PD, Kent TA, Savitz SI, Lo EH, Group S (2009) Update of the stroke therapy academic industry roundtable preclinical recommendations. Stroke 40(6):2244-2250. doi:10.1161/STROKEAHA.108.541128

134. Kilkenny C, Browne WJ, Cuthill IC, Emerson M, Altman DG (2010) Improving bioscience research reporting: the ARRIVE guidelines for reporting animal research. PLoS Biol 8(6):e1000412. doi:10.1371/journal.pbio.1000412

135. Percie du Sert N, Alfieri A, Allan SM, Carswell HV, Deuchar GA, Farr TD, Flecknell P, Gallagher L, Gibson CL, Haley MJ, Macleod MR, McColl BW, McCabe C, Morancho A, Moon LD, O'Neill MJ, Perez de Puig I, Planas A, Ragan CI, Rosell A, Roy LA, Ryder KO, Simats A, Sena ES, Sutherland BA, Tricklebank MD, Trueman RC, Whitfield L, Wong R, Macrae IM (2017) The IMPROVE guidelines (ischaemia models: procedural refinements of in vivo experiments). J Cereb Blood Flow Metab. doi:1 0.1177/0271678X17709185 